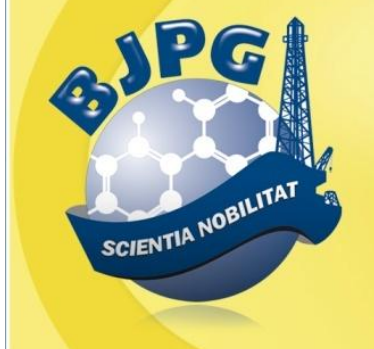

\title{
BRAZILIAN JOURNAL OF PETROLEUM AND GAS
}

Journal Homepage: www.portalabpg.org.br/bjpg

\section{USE OF CONTROL VARIABLES TO IMPROVE THE PERFORMANCE OF WATER AND POLYMER FLOODING STRATEGIES}

\author{
${ }^{a}$ Botechia, V. E. ${ }^{1}$; ${ }^{\text {a }}$ Schiozer, D. J. \\ ${ }^{a}$ CEPETRO/FEM - UNICAMP, Campinas, São Paulo, Brazil
}

Received: 06.06.2017 / Revised: 08.11.2017 / Accepted: 08.11.2017 / Published on line: 21.12.2017

\begin{abstract}
In oil industry, decisions related to field development take into consideration scenarios that involve many uncertainties and high investments. Thus, a comprehensive decision analysis process is necessary to select the production strategy that maximizes field performance considering these uncertainties. For the selection of a production strategy, two main groups of optimization variables may be considered: design and control variables. The design variables relate to the development of the field, and cannot be altered after the implementation of the strategy (e.g. capacity of the platform, number and position of wells). On the contrary, control variables relate to the management of the field, and can be altered daily by the companies (e.g. production and injection rates). However, even with a robust production strategy selection process, unexpected or undesirable events can occur and decrease the economic efficiency of the project. The objective of this work is to evaluate the use of control variables when undesirable events occur after the implementation of a production strategy, to improve the economic performance of the project. Two production strategies are used: one that uses only water flooding and other one prepared for polymer flooding. The simulation model is based on a heterogeneous heavy oil offshore field. Two approaches (undesirable events) are considered in this work: (1) polymer degradation and (2) a geologic model that is different than the expected one. The results show that the economic performance can be improved greatly by simply adjusting the control variables for the described situations. Moreover, the gain in the polymer flooding case is higher than for water flooding, because of the higher number of optimization variables, such as polymer solution concentration and slug size, giving more flexibility to this kind of project.
\end{abstract}

\section{KEYWORDS}

numerical simulation; field management; economic analysis; polymer flooding

\footnotetext{
${ }^{1}$ To whom all correspondence should be addressed. Address: CEPETRO/FEM - UNICAMP, Caixa Postal 6052, Campinas, São Paulo, Brazil. ZIP Code: 13.083-970 | e-mail: botechia@dep.fem.unicamp.br doi:10.5419/bjpg2017-0017
} 


\section{INTRODUCTION}

Decision analysis is a structured way of thinking that allows the decision maker to visualize the possible actions that can be taken in the face of a given problem or procedure (Cunha, 2007), combining the elements of risk and the uncertainty in a quantitative manner (Hayashi et al., 2007). In oil industry, a fundamental decision in regards to the selection of a production strategy seeks to reach the best field performance. When using enhanced techniques, such as polymer flooding (Needham \& Doe, 1987; Sorbie, 1991), this kind of process becomes even more important, since there are more phenomena and uncertainties involved.

However, it is important to highlight that the decision analysis does not eliminate the risk and the uncertainty in the decision-making, but it provides tools to evaluate, quantify, and understand the risk involved in the process (Newendorp \& Schuyler, 2000). Thus, after conducting a decision analysis process, and the strategy is already implemented, some unexpected or undesirable events may occur, which can cause a decrease in the economic efficiency of the project.

In optimization processes, the optimization variables can be divided into two main groups: design variables (G1) and control variables (G2) (Gaspar et al., 2016). The difference between them is that $\mathrm{G} 1$ variables cannot be changed after the strategy is implemented (some examples are the number and location of the wells and platform capacity), while $\mathrm{G} 2$ variables can be altered during daily operations of the companies (some examples are production and injection rates). Lamas and Schiozer (2016) analyzed the effects of G1 and G2 variables for different production strategies, considering water and polymer flooding.

This paper aims to evaluate the effects of G2 variables when undesirable events occur after the decision-making process, in which the production strategy is already defined. The objective is to improve the economic return of some project options by the re-optimization of control variables, avoiding larger losses caused by undesirable events. To achieve that goal, two production strategies are used: one considering polymer flooding (strategy SP) and another one considering water flooding (strategy SW).

\section{METHODOLOGY}

Two different approaches are addressed in this work, representing different events that can occur after a production strategy implementation:

(a) Occurrence of polymer degradation;

(b) Four years after defining the strategy, the geological uncertainties are reduced to a level that the simulation model can be treated as deterministic (i.e. the uncertainties can be disregarded), and it is different from the model that the strategy was optimized for.

For approach (a), we use only the strategy that was optimized considering polymer flooding (SP), while in approach (b) we apply also the optimized strategy considering water flooding (SW). Besides the different recovery mechanisms, other differences between the strategies are the number and the location of wells (see Application Section).

The control variables optimization process consists in the maximization of Net Present Value (NPV - Equation 1). The NPV consists in the sum of cash flows over time, brought to a present value through a discount rate. In this work, the cash flows consist in revenues from oil production; costs from oil and water production; costs from water injection; and, for polymer flooding strategy, the costs from polymer injection.

The optimization variables are listed below:

1) Well BHP pressure to control production and injection rates;

2) Economic water cut limit for well shutdown;

3) Polymer bank size and start date (only for polymer flooding strategy);

4) Concentration of polymer solution (only for polymer flooding strategy).

$N P V=\sum_{i=0}^{n} \frac{C F_{i}}{(1+r)^{t_{i}}}$

The methodology of approach (a) consists of the following steps:

- Application of the undesirable event in the strategy (degradation); 


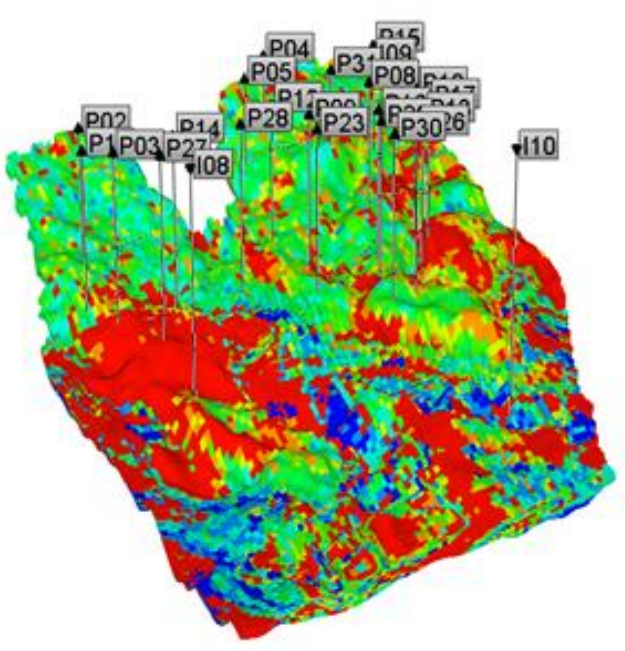

(a)

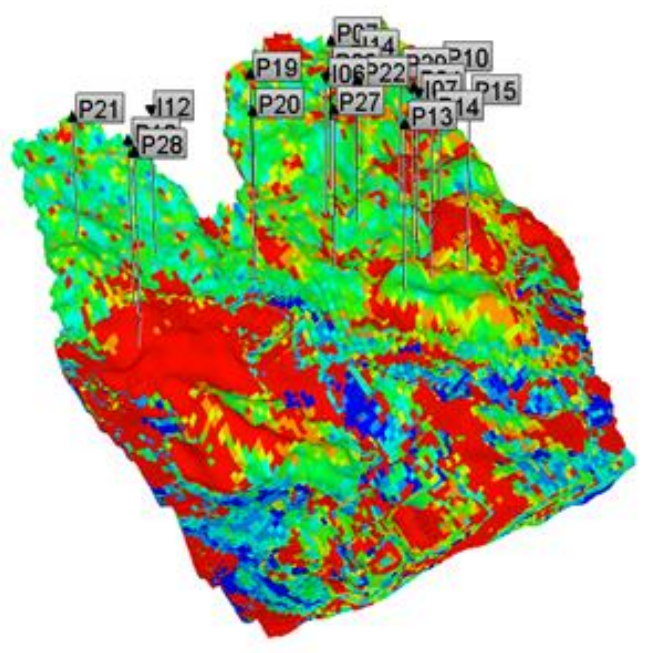

(b)

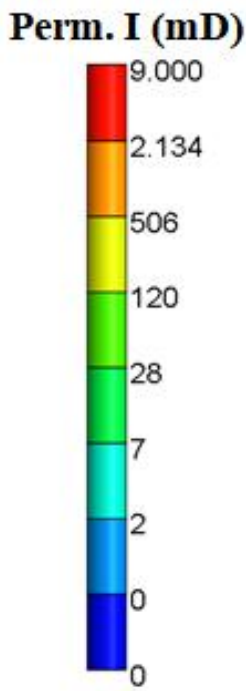

Figure 1. 3D view of horizontal permeability map in logarithmic scale and production strategies considering (a) water flooding and (b) polymer flooding.

- Optimization of control variables, aiming to maximize the NPV;

- Analysis of the results.

The methodology of approach (b) consists of the following steps:

- Application of strategies SW and SP in some representative models (RM);

- Optimization of control variables for the strategies in each representative model, after four years of the start of the simulation;

- Analysis of the results.

The Representative Models (RM) correspond to the variability of the uncertainties of the geological model, combining them in a small number of simulation models (Marques et al., 2013; Schiozer et al., 2015; Meira et al., 2016). See in the Application Section the main parameters of the representative models used in this work.

Specificities and more details about each approach are addressed in the next topics.

\section{APPLICATION}

The base simulation model used in this work represents a heterogeneous heavy oil offshore field. Figure 1 shows the tridimensional permeability map and the strategies considering water flooding (SW - left) and polymer flooding (SP - right). Strategy SW has 24 wells (21 producers and 3 injectors) and strategy SP has 19 wells (15 producers and 4 injectors). Table 1 shows the main parameters of the model, while Table 2 shows the economic parameters used for NPV calculation. The Dykstra-Parsons coefficient of this model is about 1.7025 .

Table 3 shows some parameters of the representative models used in this work.

\subsection{First Approach - polymer degradation}

This first approach applies only for polymer flooding strategy (SP). Polymer flooding is a chemical enhanced oil recovery that consists of adding polymer to the water injection, increasing its viscosity and improving the mobility ratio and the sweep efficiency (Needham \& Doe, 1987; Lake, 1989). Polymer degradation (Davison \& Mentzer 1982; O'Leary et al., 1987; Seright et al., 2009) refers to any process that can break down the molecular structure of the polymer macromolecule (Sorbie, 1991). In the commercial simulator used in this work, degradation is treated as a kinetic reaction, in which the kinetic factor (RRFT) is calculated according to Equation 2. In this equation, $t_{1 / 2}$ is polymer half-life time (period in 
Table 1. Main parameters of the model.

\begin{tabular}{cc}
\hline Parameter & Value \\
\hline Permeability $(\mathrm{mD})$ & 1 to 9000 (average $~ 1740)$ \\
Porosity & 0.13 to 0.32 (average $\sim 0.22$ ) \\
Depth $(\mathrm{m})$ & 1921 to 2706 (average $\sim 2350)$ \\
Temperature $\left({ }^{\circ} \mathrm{C}\right)$ & $78^{\circ} \mathrm{C}$ \\
Average Pressure $(\mathrm{kPa})$ & 23668 \\
Average Oil Viscosity $(\mathrm{cP})$ & 174 \\
Oil API & 15 \\
\hline
\end{tabular}

Table 2. Economic parameters.

\begin{tabular}{ccc}
\hline \multirow{2}{*}{ Market Values } & Discount Rate (\%) & 9 \\
& Oil Price (USD/bbl) & 75 \\
\hline \multirow{3}{*}{ Taxes } & Special Taxes on G. Revenue (\%) & 9.25 \\
& Corporate Taxes (\%) & 34 \\
& Royalties (\%) & 10 \\
\hline \multirow{2}{*}{ Costs } & Oil Production (USD/bbl) & 10 \\
& Water Production (USD/bbl) & 1 \\
& Water Injection (USD/bbl) & 1 \\
& Abandonment (USD Millions) & $10 \%$ of platform cost \\
\hline \multirow{2}{*}{ Investments } & Initial Investment (USD Millions) & 1000 \\
& Wells (USD Millions) & 100 \\
\hline Polymer cost & Platform (USD Millions) & Variable \\
\hline
\end{tabular}

Table 3. Characteristics of the representative models used in this work.

\begin{tabular}{ccccc}
\hline RM & $\begin{array}{c}\text { Aver. Perm. } \\
(\mathbf{m D})\end{array}$ & Aver. Por. & $\begin{array}{c}\text { Av. Oil Visc. } \\
(\mathbf{c P})\end{array}$ & $\begin{array}{c}\text { Rock Comp. } \\
\left(\mathbf{1 0 ^ { - 6 }} \mathbf{1 / \mathbf { k P } )}\right.\end{array}$ \\
\hline 1 & 1740 & 0.218 & 173 & 4.10 \\
2 & 2932 & 0.211 & 156 & 5.33 \\
3 & 2085 & 0.225 & 191 & 4.10 \\
4 & 1873 & 0.224 & 173 & 3.48 \\
5 & 1972 & 0.209 & 182 & 3.48 \\
6 & 2169 & 0.210 & 173 & 4.10 \\
7 & 1124 & 0.211 & 165 & 3.48 \\
\hline
\end{tabular}

which the viscosity of polymer solution decreases to half of the original). In this study, two values for half-life time were considered: 1 year (stronger degradation) and 2 years (weaker degradation). Hence, the values obtained for RRFT were 0.00189723 and 0.00094907 , respectively.
$R R F T=1-\exp \left(\frac{-\operatorname{Ln}(2)}{t_{1 / 2}}\right)$

Another possibility tested here is the injection of water in strategy SP to verify if this option presents a better or worse performance than that of the SP with degraded polymer. 
Table 4. Gain with G2 optimization for strategy SP considering degradation or injection of water.

\begin{tabular}{cccc}
\hline Strategy / Situation & $\begin{array}{c}\text { NPV } \\
\left(\mathbf{1 0}^{\mathbf{6}} \mathbf{U S D}\right)\end{array}$ & $\begin{array}{c}\text { NPV } \\
\text { difference in } \\
\text { relation to } \\
\text { SP (\%) }\end{array}$ & $\begin{array}{c}\text { NPV improvement } \\
\text { with G2 } \\
\text { optimization (\%) }\end{array}$ \\
\hline SP & 2517 & - & - \\
\hline SP - injecting water & 1950 & -23 & - \\
SP - injecting water - G2 optim. & 2047 & -19 & - \\
\hline SP - Deg. HL 1 year & 2035 & -19 & 21 \\
SP - Deg. HL 1 year - G2 optim. & 2459 & -2 & - \\
\hline SP - Deg. HL 2 years & 2131 & -15 & 16 \\
\hline SP - Deg. HL 2 years - G2 optim. & 2462 & -2 & \\
\hline
\end{tabular}

Table 5. Differences in cumulative oil production and total mass of injected polymer in all situations addressed in this work.

\begin{tabular}{|c|c|c|c|c|c|}
\hline Strategy / Situation & $\begin{array}{c}\mathrm{Np} \\
\left(10^{6} \mathrm{~m}^{3}\right)\end{array}$ & $\begin{array}{l}\text { Np difference in } \\
\text { relation to SP (\%) }\end{array}$ & $\begin{array}{l}\text { Np improvement } \\
\text { with G2 optim. } \\
\text { (\%) }\end{array}$ & $\begin{array}{l}\text { Mass of } \\
\text { Injected } \\
\text { Polymer } \\
\left(10^{6} \mathrm{~kg}\right)\end{array}$ & $\begin{array}{l}\text { Difference } \\
\text { in pol. } \\
\text { mass in } \\
\text { relation to } \\
\text { SP (\%) }\end{array}$ \\
\hline SP & 76 & - & - & 185 & - \\
\hline SP - injecting water & 58 & -24 & - & - & - \\
\hline SP - injecting water - G2 optim. & 59 & -22 & 2 & - & - \\
\hline SP - Deg. HL 1 year & 66 & -13 & - & 217 & 17 \\
\hline SP - Deg. HL 1 year - G2 optim. & 69 & -9 & 5 & 14 & -92 \\
\hline SP - Deg. HL 2 years & 68 & -11 & - & 213 & 15 \\
\hline SP - Deg. HL 2 years - G2 optim. & 70 & -8 & 3 & 67 & -64 \\
\hline
\end{tabular}

Table 4 shows the NPV values for strategy SP, including the situation when polymer is degraded and also the situation when water is injected in this strategy instead of polymer, before and after G2 variables optimization.

Botechia et al. (2016) showed that it is important to consider the recovery mechanism when optimizing the production strategy (G1 variables). One can see in Table 4 that the worst situation is the injection of water in the strategy that was prepared for polymer flooding $(23 \%$ of financial loss), being even worse than polymer degradation. The optimization of control variables could improve the performance in $5 \%$ for this case, reducing the loss from 23 to $18 \%$.

The highest gain due to $\mathrm{G} 2$ optimization occurred in the case with stronger degradation (half-life of 1 year), with an increase of $21 \%$ in NPV in comparison with the variables not optimized. Thus, the strategy presented almost the same efficiency of the base case, losing only $2 \%$ in economic performance. Similar behavior occurred for the case with weaker degradation (half-life of 2 years), reducing the financial loss from 15 to $2 \%$.

Table 5 shows the differences in cumulative oil production ( $\mathrm{Np}$ ) for the situations addressed in this work. It also presents the variation in the total mass of the injected polymer. Note that the improvement in $\mathrm{Np}$ due to control variables optimization is not as great as the improvement in NPV (the best case could improve the recovery in $5 \%$, diminishing the production loss caused by polymer degradation from -13 to $-9 \%$ ). 


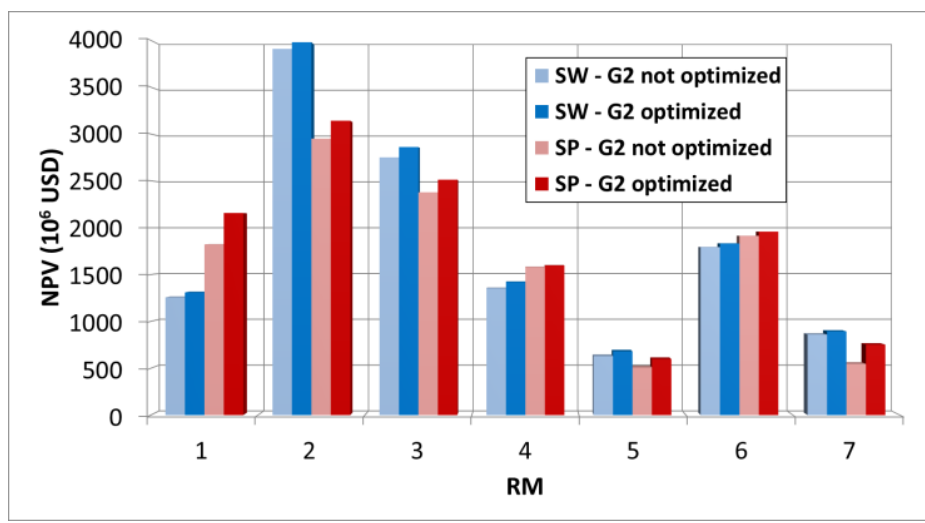

Figure 2. NPV for strategies SW and SP applied for seven different representative models, before and after G2 variables optimization.

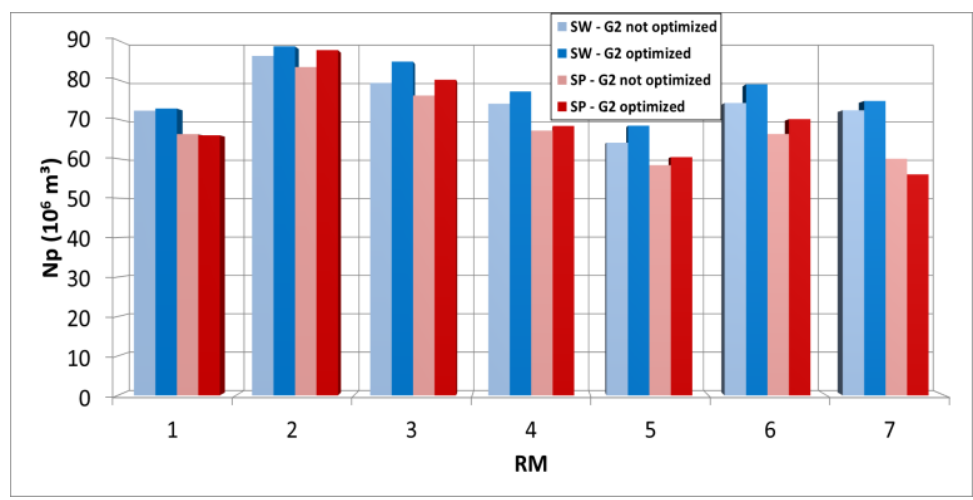

Figure 3. Np for strategies SW and SP applied for seven different representative models, before and after G2 variables optimization.

However, the amount of injected polymer increases with degradation, and this amount is adjusted after the $\mathrm{G} 2$ optimization. In fact, when a polymer degrades, more of the polymer is spent (reflecting in the economic performance), but with less efficiency, since the solution viscosity decreases in this case. After adjusting the control variables, the polymer solution concentration and the bank size decrease, impacting the amount of injected polymer and, hence, the money spent in the project. This adjustment in the amount of injected polymer is the main reason for the great improvement in NPV.

The fact that polymer flooding has more control variables (polymer solution concentration and bank size) than the water flooding strategy leads to higher gains for that technique in relation to the case in which only water is injected. Hence, the economic improvement in the case of water injection is not as great as in the case of the injection a degradable polymer.

\subsection{Second Approach - geologic model is different than initially expected}

The idea here is to apply strategies SW and SP in some representative models and optimize G2 variables, to verify if it is possible to improve the strategy without changing project parameters.

Strategies SW and SP were submitted to simulation in 7 representative models (RM).

Figure 2 compares the NPV obtained before and after $\mathrm{G} 2$ variables optimization for the water and polymer flooding strategies in the seven representative models, while Figure 3 makes the same kind of comparison, but for cumulative oil produced.

In all cases, it was possible to improve the performance of the strategy by changing control variables. However, if the NPV for the strategy SW is higher than SP in a determined model (for 
Table 6. Average variations in NPV, Np and polymer injection cost.

\begin{tabular}{cccc}
\hline Strategy & $\begin{array}{c}\text { NPV Average } \\
\text { Variation }\end{array}$ & $\begin{array}{c}\text { Np Average } \\
\text { Variation }\end{array}$ & Polymer Cost Average Variation \\
\hline SW & $4 \%$ & $4 \%$ & - \\
SP & $13 \%$ & $2 \%$ & $-28 \%$ \\
\hline
\end{tabular}

example, SW strategy was better than polymer flooding in RM2, RM3, RM5, and RM7), the strategy SP is not capable of overcoming the performance of SW, even with the G2 variables optimization. The same is valid for the models in which SP is better than SW (RM1, RM4, RM6 e RM7); the G2 optimization can improve the performance of SW strategy in these models, but is not enough to surpass SP performance. This means that project variables (group G1, like number and location wells) have more impact in these results than $\mathrm{G} 2$ variables.

Another point to note is that in some cases for polymer flooding strategies there was a reduction in produced oil after optimization (RM1 and RM7 Figure 3). However, this reduction was followed by a significant decrease in the polymer injection cost (which means less mass of polymer needed to be injected to improve performance). This result shows the importance of considering polymer cost in optimization processes of polymer flooding, since an increment in oil production may not result in better economic performance, due to these extra costs related to polymer injection.

The average improvement in NPV was significantly higher for SP strategy in relation to SW (13\% against $4 \%$ - Table 6$)$. This difference is caused by the highest flexibility in polymer flooding case, due to higher number of G2 variables, as already addressed in the previous approach. However, this increase in NPV is mainly due to the reduction in polymer injection cost rather than in the increase of oil production. In fact, the average increase in oil production was higher for water flooding in relation to polymer flooding ( $4 \%$ against $2 \%)$.

It is noteworthy that this approach considers that the production strategy is already implemented, so that only control variables can be altered. If the production strategy is not developed yet, it is possible to optimize G1 (project) variables.

\section{CONCLUSIONS}

This work presented a method to improve the performance of a production strategy after its implementation, in case some unexpected or undesirable event occurs, through the reoptimization of control (G2) variables. It considers strategies with design variables (G1) optimized for water and polymer flooding. Two approaches were addressed in this paper: occurrence of polymer degradation and the finding that the geologic model is different than it what was initially expected.

Both strategies (water and polymer flooding) had their performance increased after $\mathrm{G} 2$ variables optimization, but polymer-flooding strategy had the highest gain. This happened because this mechanism has more control variables to be optimized in relation to water flooding (slug size and concentration), giving more flexibility to this kind of project in relation to the water flooding one. Moreover, in some cases, the increment in economic performance is mainly due to reduction in polymer cost (less polymer mass injected) than to increase in oil production. Thus, it is important to analyze this kind of project with economic indicators, since it generates extra costs and an increase in oil production does not necessarily reflect a higher economic gain.

The procedure shown in this paper can be adapted for production strategies that use other types of recovery mechanisms (changing or including other variables) and for other kind of unexpected events.

\section{ACKNOWLEDGEMENTS}

The authors would like to thank UNISIM, DE-FEM, CEPETRO, PETROBRAS, STATOIL, ANP, and Foundation CMG for supporting this work, and CMG for software licenses. 


\section{NOMENCLATURE}

G1 Design variables

G2 Control variables

HL Half-life

Ln Natural logarithm

Np Cumulative oil produced

NPV Net present value

RM Representative model

RRFT Kinetic factor of degradation kinetic reaction

SW Strategy optimized for water flooding

SP Strategy optimized for polymer flooding

$\mathrm{t}_{1 / 2}$ Half-life time

\section{REFERENCES}

Botechia, V. E.; Correia, M. G.; Schiozer, D. J. A model-based production strategy selection considering polymer flooding in heavy oil field development. SPE 180838. In: SPE Trinidad and Tobago Section Energy Resources Conference, Trinidad and Tobago, 2016.

https://doi.org/10.2118/180838-MS

Cunha, J. C., Recent developments on application of decision analysis for the oil industry. SPE 108703. In: 2007 International Oil Conference and Exhibition in Mexico, Veracruz, Mexico, 2007. https://doi.org/10.2118/108703-MS

Davison, P.; Mentzer, E. Polymer flooding in north sea reservoirs. SPE 9300-PA. SPE Journal, Vol. 22, Issue 3, pp. 353-362, 1982.

https://doi.org/10.2118/9300-PA

Gaspar, A. T. F. S.; Barreto, C. E. A.; Mazo, E. O M.; Schiozer, D. J. Assisted process for design optimization of oil exploitation strategy. Journal of Petroleum Science and Engineering, v. 146, p. 473488, 2016.https://doi.org/10.1016/j.petrol.2016.05.042

Hayashi, S. H. D.; Ligero, L. L.; Schiozer, D. J. Decision-making process in development of offshore petroleum fields. SPE 107737. In: 2007 SPE Latin American and Caribbean Petroleum Engineering Conference, Buenos Aires, Argentina, 2007. https://doi.org/10.2118/107737-MS

Lake, L. W., Enhanced Oil Recovery. New Jersey, USA: Prentice Hall, 1989.
Lamas, L. F.; Schiozer, D. J. Comparison of number and position of wells for water and polymer flooding project. International Journal of Modeling and Simulation for Petroleum Industry, v. 9, N. 2, pp. 33-40, 2016.

Marques, M. D.; Gaspar, A. T.; Schiozer, D. J., Use of oil reservoir simulation to estimate value of flexibility. SPE 164878. In: EAGE Annual Conference \& Exhibition incorporating Europec, London, United Kingdom, 2013.

https://doi.org/10.2118/164878-MS

Meira, L. A. A.; Coelho, G. P.; Santos, A. A. S.; Schiozer, D. J. Selection of representative models for decision analysis under uncertainty. Computers \& Geosciences, v. 88, p. 67-82, 2016. https://doi.org/10.1016/j.cageo.2015.11.012

Needham, R. B.; Doe, P. H. Polymer flooding review. SPE 17140. Journal of Petroleum Technology, v. 39, n. 12, p. 1503-1507, 1987. https://doi.org/10.2118/17140-PA

Newendorp, P. D; Schuyler, J., Decision Analysis for Petroleum Exploration, $2^{\text {nd }}$ Edition. Colorado, USA: Planning Press ${ }^{\mathrm{TM}}, 2000$.

O'Leary, W. B.; Boivin, J. W.; Dasinger, B.; Beck, D.; Goldman, L. M.; Wernau, W. C. Biocide evaluation against sessile xanthan polymerdegrading bacteria. SPE 13588. SPE Reservoir Engineering, v. 2, n. 4, p. 647-652, 1987.

https://doi.org/10.2118/13588-PA

Schiozer, D. J.; Santos, A. A. S.; Drumond, P. S., Integrated model based decision analysis in twelve steps applied to petroleum fields development and management. SPE 174370. In: Europec 2015, Madrid, Spain, 2015. https://doi.org/10.2118/174370$\underline{\mathrm{MS}}$

Seright, R. S.; Campbell, A. R.; Mozley, P. S., Stability of partially hydrolyzed polyacrylamides at elevated temperatures in the absence of divalent cations. SPE 121460. In: SPE International Symposium on Oilfield Chemistry. Texas, USA, 2009. https://doi.org/10.2118/121460-MS

Sorbie, K. S. Polymer-improved Oil Recovery. USA and Canada: CRC Press Inc., 1991. https://doi.org/10.1007/978-94-011-3044-8 